\title{
Composite Axial Flow Propulsor for Small Aircraft
}

\author{
R. Poul, D. Hanus
}

This work focuses on the design of an axial flow ducted fan driven by a reciprocating engine. The solution minimizes the turbulization of the flow around the aircraft. The fan has a rotor - stator configuration. Due to the need for low weight of the fan, a carbon/epoxy composite material was chosen for the blades and the driving shaft.

The fan is designed for optimal isentropic efficiency and free vortex flow. A stress analysis of the rotor blade was performed using the Finite Element Method. The skin of the blade is calculated as a laminate and the foam core as a solid. A static and dynamic analysis were made. The RTM technology is compared with other technologies and is described in detail.

Keywords: axial flow fan design, ducted fan, composite blades.

\section{Introduction}

Our work deals with many aspects of the design of an axial-flow, one-stage, ducted fan driven by a Yamaha four-stroke, four-cylinder reciprocating engine with a power output of $110 \mathrm{~kW}$. An airplane with this propulsion is expected to have distinctly low drag, because of the location of the fan inside the hull. This will make the airplane aerodynamically smoother than classic airplanes with a tractor propeller. Such a solution minimizes the disturbance of the flow around the aircraft, so a significant part of the wetted surface of the airplane is expected to work in the laminar regime. This fan has a rotor - stator configuration. The need for low weight of the fan is the reason for choosing a carbon/epoxy composite material for the blades and driving shaft connecting the engine with the fan. This work is divided into 6 main parts: aerodynamic design, choice of production technology, evaluation of the quasistatic and dynamic loads of the rotor, calculation of the properties of the composite materials, and rotor FEA. Because of the great complexity of the work, other aspects, such as a strength and stiffness analysis of the stator vanes and the solution of the cooler, are omitted.

\section{Aerodynamic design}

A method for aerodynamic design of a fan is described in [1]. The fan is designed for optimal isentropic efficiency in the design regime and on the assumption that the distribution of the tangential component of the velocity corresponds to a free vortex. The rotor blade and stator vane profiles have the NACA 65 A 010 profile, parabolically modified in the rear part and wrapped around the circular arc centerline.

The design point of the fan is airplane velocity equal to $0 \mathrm{~m} / \mathrm{s}$ at an altitude of $0 \mathrm{~m}$ of ISA. The blades and vanes are divided into 8 sections for geometry calculation purposes. The rotor contains 14 blades and the stator contains 20 vanes. The following method is used for calculating the geometry (see Fig. 1).

The incoming air angle is calculated as:

where $u \quad$ is tangential velocity, and

$w_{a x}$ is axial velocity of air.

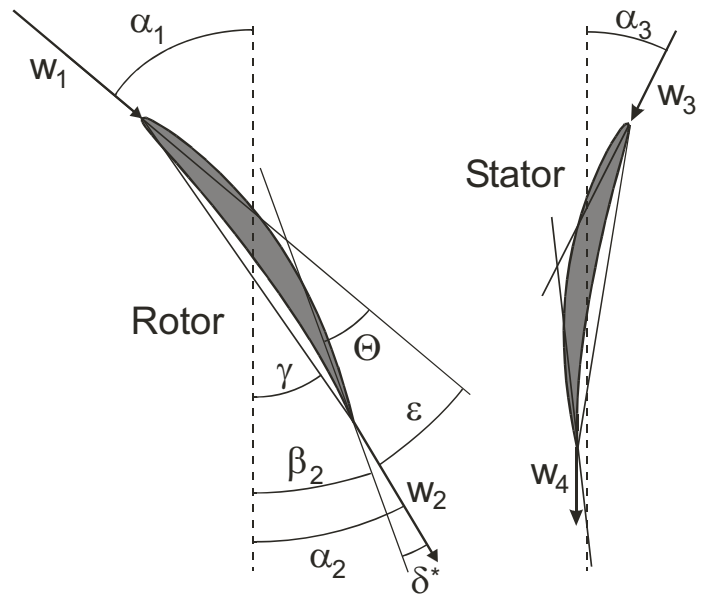

Fig. 1: Symbols used for a description of the rotor blade and stator vane geometry

The angle of the air leaving the rotor blade is:

$$
\alpha_{2}=\operatorname{arctg}\left(\operatorname{tg}\left(\alpha_{1}\right)-\frac{P}{m^{\prime} \cdot w_{a x} \cdot u}\right),
$$

where $m^{\prime} \quad$ is mass flow rate, and

$P \quad$ is power input.

The air deflection is then:

$$
\varepsilon=\alpha_{1}-\alpha_{2}
$$

The proper blade/vane density is chosen according to Fig. 2.

The deviation angle is obtained from the Constant rule modified for angle of attack equal to zero

$$
\delta^{*}=\frac{0.23 \varepsilon \sqrt{\frac{s}{c}}}{1-0.23 \sqrt{\frac{s}{c}}},
$$

where $\frac{s}{c}$ is relative blade/vane density.

The stator calculation is accomplished by analogy.

For technological reasons the hub and duct diameters are constant along the fan axis. The hub diameter is $300 \mathrm{~mm}$, and the duct diameter is $580 \mathrm{~mm}$. The next task was to check the 


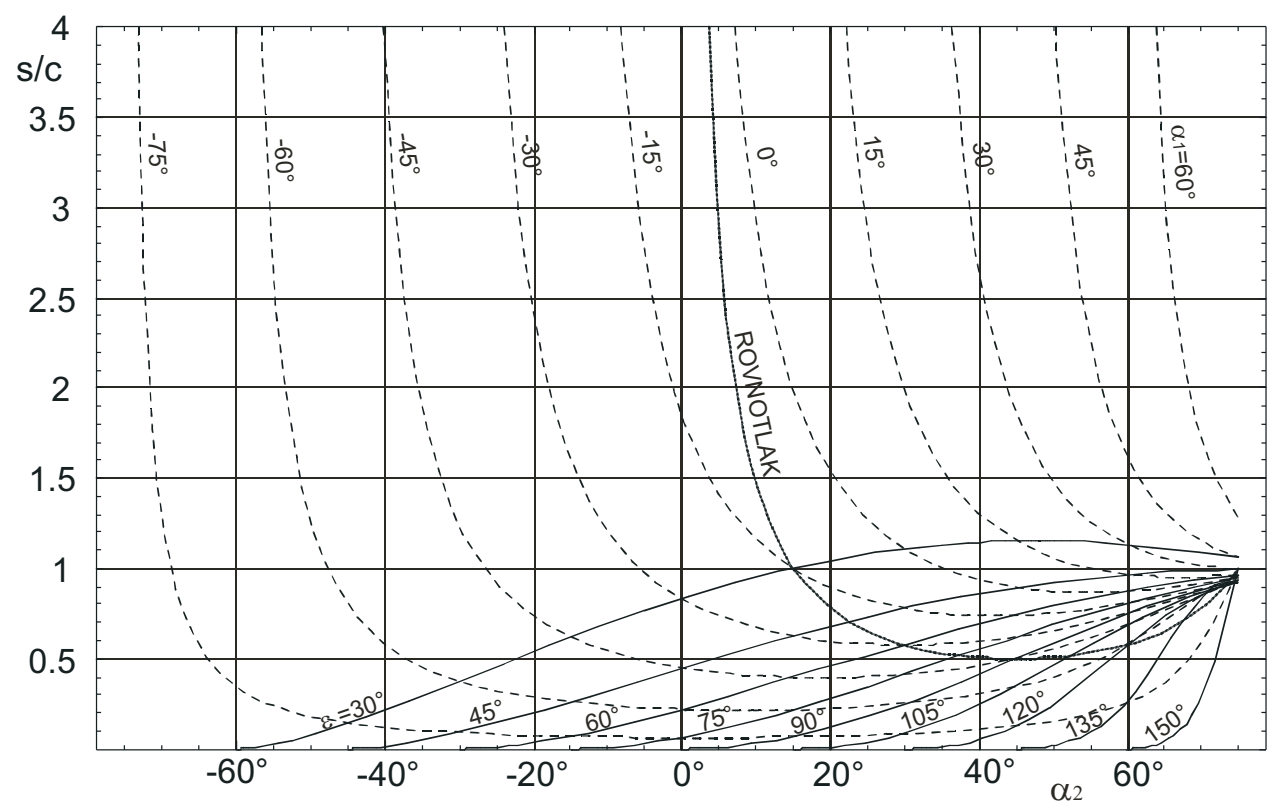

Fig. 2: Diagram from [1] used for choosing the optimum blade/vane relative density

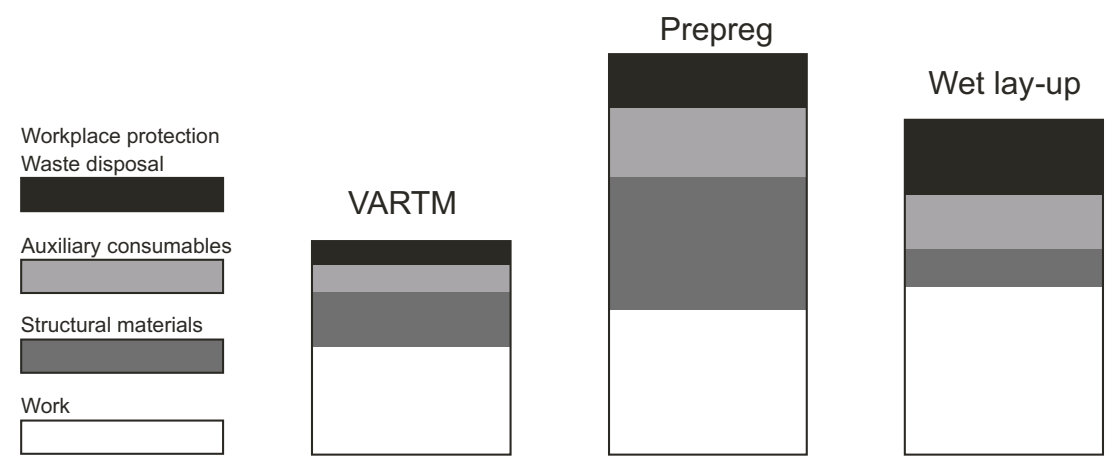

Fig. 3: Comparison of the production costs for the composites

Mach number on the blade surface to prevent the occurrence of shock waves. Two approximate methods were used for this check. The first was to find the local velocity maximum of the blade compared with the mean velocity between the rotor blades. The second method was based on lift and drag coefficients, and is described in [1].

\section{Technology}

In this section only the rotor blade is studied. The rotor blade will be made of carbon reinforced epoxy resin and a foam core, with the dovetail lock made of Al-alloy. The most suitable technology for composite production is chosen in this section.

Three composite production technologies are compared in this work: 1) wet lay-up is the cheapest from the tooling point of view, but the mechanical properties would vary considerably from piece to piece, 2) prepreg has the most expensive resin curing and storage conditions, but properties such as the fibre volume fraction of the composite will vary only slightly 3) vacuum assisted resin transfer molding (VARTM) was chosen as the most favourable method, in terms of both cost and technological considerations. Fig. 3 shows a comparison of the production costs.

Scheme of vacuum assisted resin transfer molding (Fig. 4).

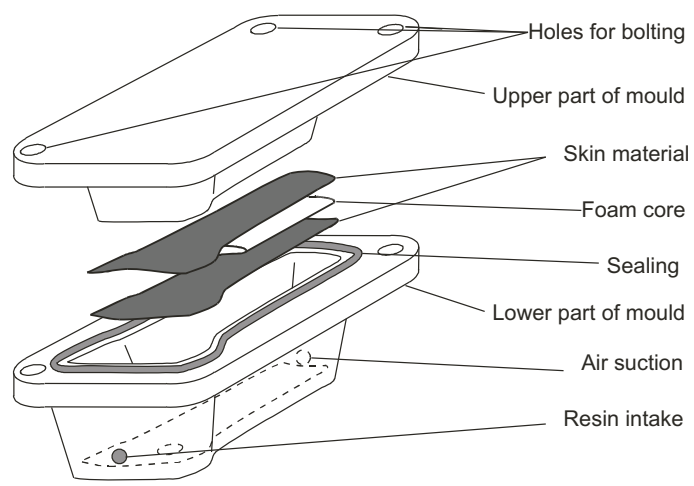

Fig. 4: Scheme of VARTM 


\section{Loads applied to rotor blades}

A rotor blade is loaded by a centrifugal force, resulting in a tensional force and a torsional moment acting in the blade axis direction, and by air pressure, which induces bending moments acting in the fan tangential and axial direction. The torsional moment in the blade axis direction induced by air pressure was neglected in this work, because of the unknown exact pressure distribution on the blade surface.

The centrifugal forces and moments are calculated directly by finite element analysis (FEA) software. The pressure forces are obtained by the following process and are applied to the FEA model.

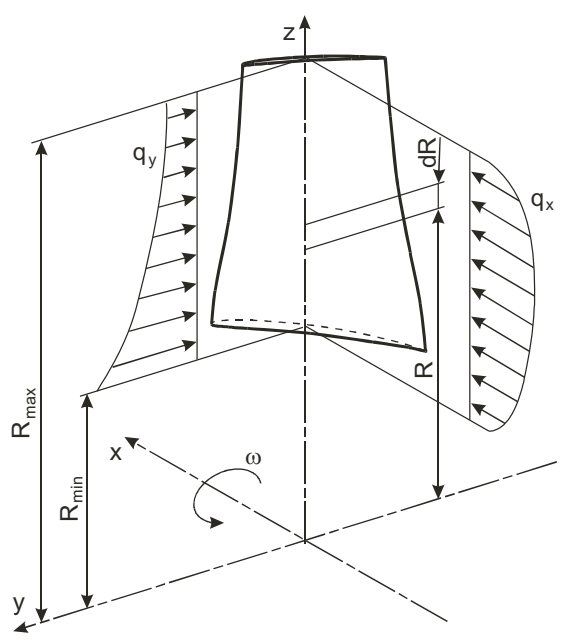

Fig. 5: Scheme of pressure forces
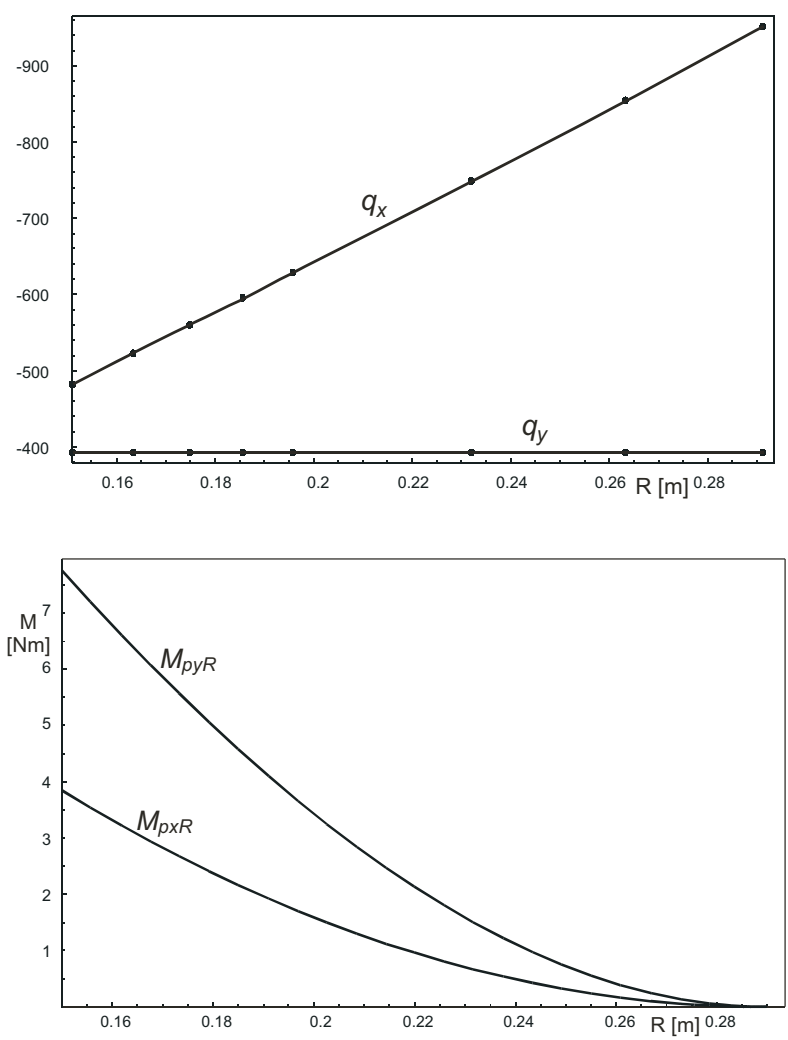

Fig. 6: Distributed pressure load and bending moment
The distributed pressure loads in directions $x$ and $y$ are calculated as:

$q_{x}=\left(p_{1 c}-p_{2 c}\right) \cdot \frac{2 \pi R}{14}$

$q_{y}=\frac{2 \pi R \cdot \rho \cdot w_{a x}\left(w_{2}-\cos \left(90-\alpha_{2}\right)-u\right)}{14}$,

where $p_{1 c}$ and $p_{2 c}$ are the total pressures in front of and behind the blade.

For explanation of other symbols, see Fig. 5 .

To obtain the distribution of the bending moment, the following integrals were applied:

$$
\begin{aligned}
& M_{p x R}=-\int_{R}^{R_{\max }} q_{y}(x-R) \mathrm{d} x, \\
& M_{p y R}=-\int_{R}^{R_{\max }} q_{x}(x-R) \mathrm{d} x .
\end{aligned}
$$

The dynamic load is produced by the airflow and by the variations in the angular velocity of a rotor typical for reciprocating engines. In our calculation, three loading sources were taken into account: 1) the wake from the union of the air inlet, which is divided into two parts -2 pulses per turn, 2) the pulses induced by passing the stator vanes -20 per turn and 3 ) the variations in angular velocity, which are 2 per turn for a four-stroke four- cylinder engine. The natural frequencies of the rotor blades must not be the same as the loading frequencies or their multiples in revolutions of working regimes. For real values, we used FEA with more angular velocities given to obtain a sufficient amount of data to create Campbell's diagram (see Fig.7).

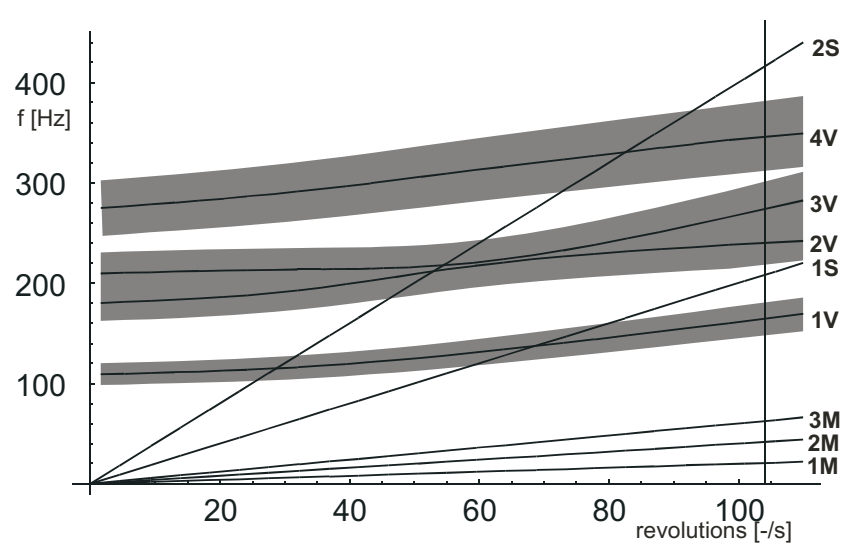

Fig. 7: Campbell's diagram of a rotor blade

Explanation:

- $1 \mathrm{~V}, 2 \mathrm{~V}, 3 \mathrm{~V}, 4 \mathrm{~V}: 1 \mathrm{st}$ to 4 th blade natural frequency, grey region around $1 \mathrm{~V}$ to $4 \mathrm{~V}$ represents $+10 \%$ of natural frequencies covering the model inaccuracy

- $1 \mathrm{M}$ : engine excitation frequency - twice per turn

- 2M, 3M: double and triple $1 \mathrm{M}$

- 1S: stator vanes excitation frequency - twenty per turn

- 2S: double $1 \mathrm{~S}$ 

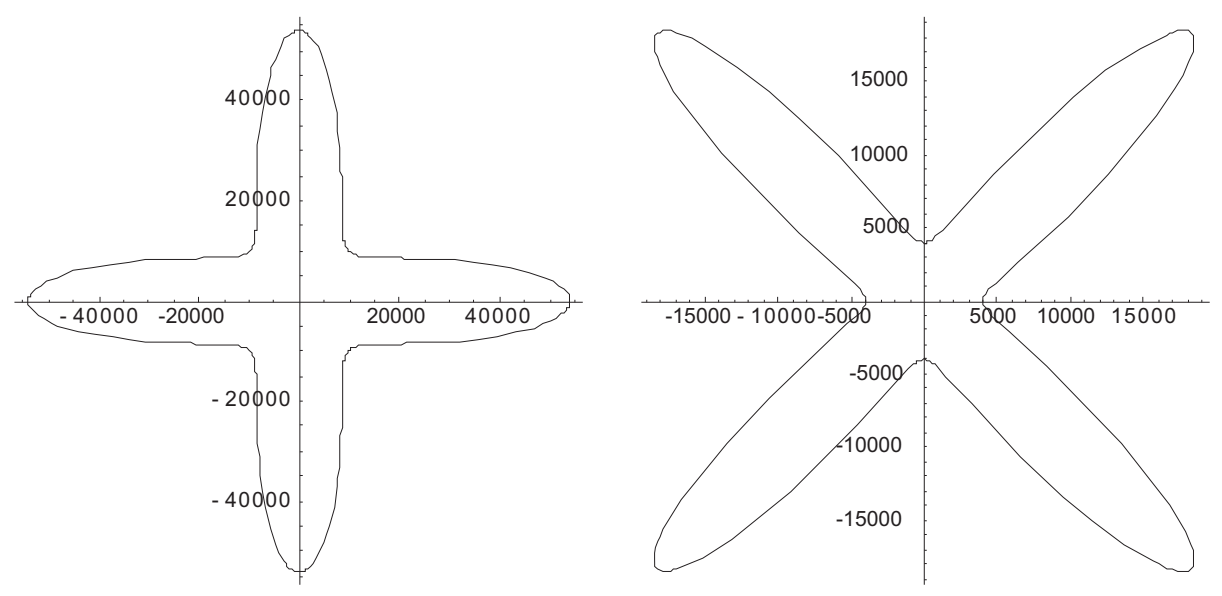

Fig. 8: Polar diagrams of Young's modulus and the shear modulus as a function of the angle between the evaluated and main direction of the material

\section{Mechanical properties of the composites}

Three types of composite are used for the rotor blade skin: high modulus carbon fabric reinforced epoxy resin, unidirectional high modulus carbon reinforced epoxy resin, and aramide fabric reinforced epoxy resin. The mechanical properties of these materials were calculated for FEA. The properties were calculated using the methods described in [6, 7], which allowed us to calculate the mechanical properties of the composite from the known properties of the fibres and of the resin. The distribution of the moduli of elasticity of high modulus carbon fabric reinforced resin is shown in Fig. 8. The axes of the polar diagram represent the directions of the warp and weft of the fabric.

\section{Rotor blade finite element analysis}

A stress analysis of the rotor blade was performed using the Finite Element Method. The calculation and modelling were accomplished using MSC Patran/Nastran. Because of the composite skin and foam core structure of the blade the following model was used: the composite skin was modeled using 4 node shell elements connected with a foam core made of wedge type solid elements. The skin of the blade was calculated as laminate. This model was loaded by centrifugal force and "air" pressure, as in the section Rotor Blade Applied Loads. From this analysis the values of the Tsai-Hill failure criterion $[6,7]$ were obtained. The same model was used for natural frequency analysis. The Tsai-Hill criterion values are presented in Fig. 9, and the stress distribution in Fig. 10.
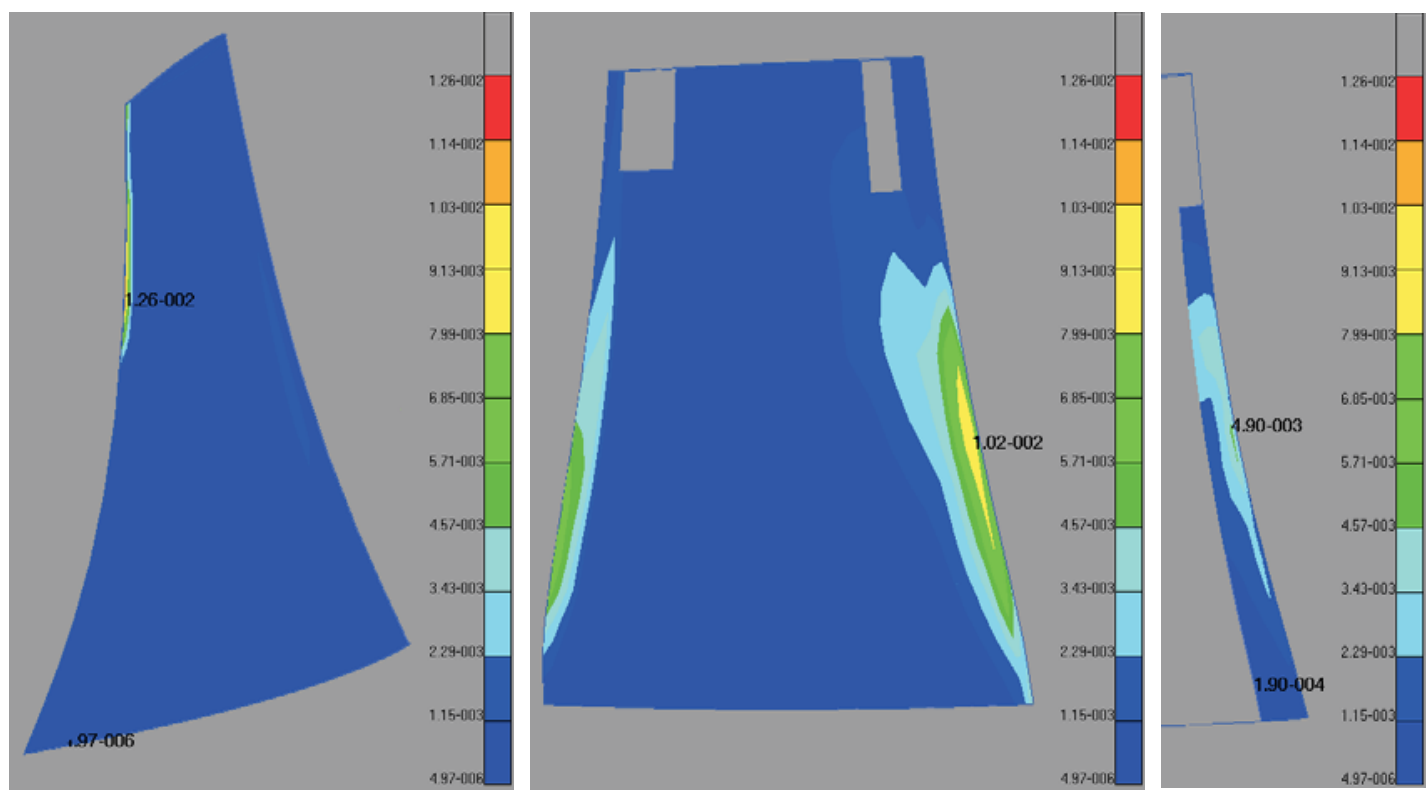

Fig. 9: Tsai-Hill failure criterion 

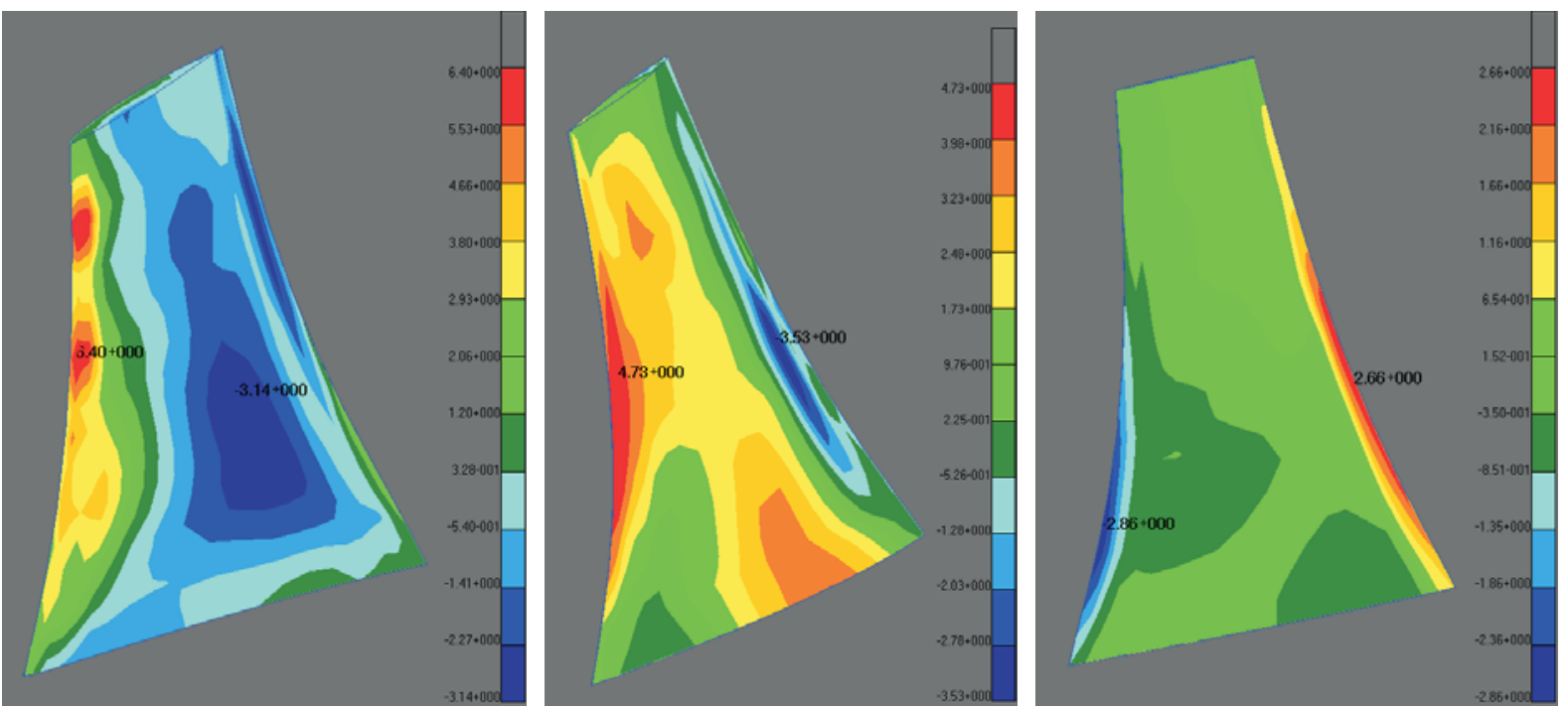

Fig. 10: Stress distribution in the first layer of the rotor blade: $\sigma_{x}, \sigma_{y}, \tau_{x y}$

\section{Design features and conclusion}

The very light composite structure of the stator and rotor of the ducted fan allows lighter corresponding supporting structures, which will significantly influence the aircraft weight. In this way the composite propulsor can be useful for very light airplanes. The proposed solution of the rotor blade is shown in Fig. 11.

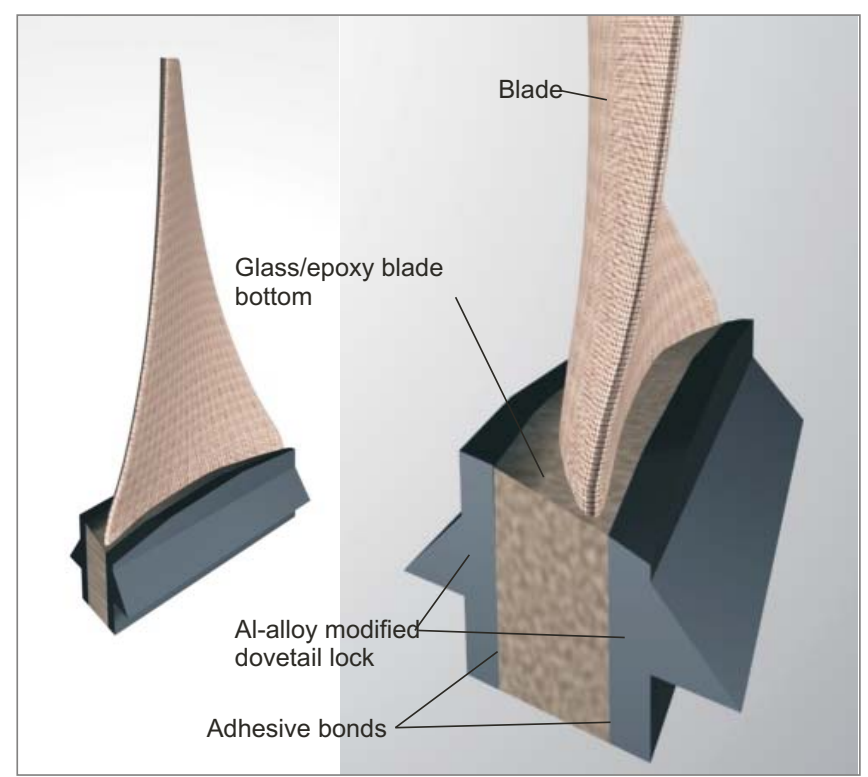

Fig. 11: Rotor blade detail

\section{References}

[1] Jerie, J.: Teorie motori, ČVUT, 1981.

[2] Statečný, J., Sedlář, F., Doležal, Z.: Pevnost a životnost leteckých turbinových motorĩ část - 1, ČVUT, 1995.
[3] Růžek, J., Kmoch, P.: Teorie leteckých motori̊ - část 1, VA Brno, 1979.

[4] Ušakov, K. A., Brusilovskij, I. V., Bušel, A. R.: Aerodynamika osouých ventilátori a jejich konstrukčni pruky. Praha: SNTL, 1962.

[5] Hanus, D.: Pohon letadel, ČVUT, 1997.

[6] Agarwal, B. D., Broutman, L. J.: Vláknové kompozity. Praha: SNTL, 1987.

[7] Gay, D.: Matériaux composites. Hermes, 1997.

[8] Hoskins, B. C., Baker, A. A.: Composite Materials for Aircraft Structures. American Institute of Aeronautics and Astronautics, Inc., 1986.

[9] Potter, K.: Resin Transfer Moulding. Chapman \& Hall, 1997.

[10] Kolář, V., Němec, I., Kanický, V.: FEM - principy a praxe metody konečných proki̊. Computer Press, 1997.

[11] Martaus, F.: Výroba presných kompozitnich díli metodou VARTM - 1. etapa řě̌ení, VZLÚ, 2001.

[12] Uher, O.: Mathematical Modeling of Behavior of Filament Wound Composite Structures. ČVUT, 2002.

Ing. Robin Poul

e-mail: robin.poul@fs.cvut.cz

Doc. Ing. Daniel Hanus, CSc.

e-mail: daniel.hanus@fs.cvut.cz

Automotive and Aerospace Engineering Department

Faculty of Mechanical Engineering

Czech Technical University in Prague

Karlovo náměstí 13

12135 Prague 2, Czech Republic 